\title{
Myotonic dystrophy and thymoma: A necropsy case report
}

\author{
Y OSHIYUKI KUROIWA, * AKIRA YAMA DA, * \\ K E N J I I K E B E, * K I NOR I K OS A K A , * \\ HIDEOSUGITA $†$ AND TOSHIKAZU MURAKAMI \\ From the Third Department of Internal Medicine,* Department of Neurology, Institute of Brain \\ Research $\dagger$ and Department of Pathology, $\ddagger$ University of Tokyo, Japan
}

SUMMARY This report describes a 46 year old woman having both thymoma and myotonic dystrophy. Laboratory studies revealed an anterior mediastinal mass, lymphocytopenia, anergic reaction to dinitrochlorobenzene and electrophysiological evidence of myotonia. Postmortem examination disclosed a thymoma with predominant proliferation of epithelial cells. This paper is the second necropsy report of myotonic dystrophy associated with thymoma.

Many diseases are associated with thymoma, including myasthenia gravis, cytopenias, cancer, hypogammaglobulinaemia, polymyositis and systemic lupus erythematosus. ${ }^{1}$ Abnormalities of the thymus, including thymoma, have consistently been found in myasthenia gravis. However, the association of thymoma with myopathies other than myasthenia gravis is very rare. In this report is described a patient having both thymoma and myotonic dystrophy.

\section{Case report}

A 46 year old Japanese housewife presented in September 1974, with the chief complaint of dyspnoea. She had noticed difficulty relaxing her grasp from childhood and developed a tendency to fall at the age of 20 years. She had had one normal delivery, one miscarriage and two stillbirths. Her elder sister and younger sister had been diagnosed as having myotonic dystrophy. Her father and paternal grandmother died of oesophageal cancer. Two cousins were mentally defective.

On physical examination, temperature was $36.2^{\circ} \mathrm{C}$, pulse rate 106 per minute, respiratory rate 32 per minute and blood pressure $112 / 94 \mathrm{mmHg}$. The respiration was laboured and the breath sounds werc absent

Address for reprint requests: Dr Yoshiyuki Kuroiwa, First Department of Internal Medicine, Hamamatsu University School of Medicine, 3600 Handa-Cho, Hamamatsu 431-31 Japan.

Accepted 22 October 1980 over the left lung field, with dullness to percussion over the same area. On neurological examination she had a myopathic facies with slight ptosis of the eyelids. She had myotonia of hand grip and percussion myotonia of the tongue and thenar eminence. The extremities showed symmetrical muscular wasting and weakness, with depressed deep tendon reflexes.

Full blood count disclosed 4,580,000 red blood cells $/ \mathrm{mm}^{3}$ and 2400 white blood cells $/ \mathrm{mm}^{3}$, with differential count of $44 \%$ segmented neutrophils, $20 \%$ non-segmented neutrophils, $9 \%$ eosinophils, $1 \%$ monocytes and $26 \%$ lymphocytes. Serum immunoglobulin concentrations were as follows; IgG $885 \mathrm{mg} / 100 \mathrm{ml}$ (normal, $1460 \pm 263 \mathrm{mg} / 100 \mathrm{ml}$ ), IgA $159 \mathrm{mg} / 100 \mathrm{ml}$ (normal, 212 $\pm 55 \mathrm{mg} / 100 \mathrm{ml}$ ) and $\mathrm{IgM} 130 \mathrm{mg} / 100 \mathrm{ml}$ (normal, $173 \pm 56 \mathrm{mg} / 100 \mathrm{ml}$ ). Delayed cutaneous hypersensitivity reaction to dinitrochlorobenzene (DNCB) was anergic. The glucose tolerance test showed a diabetic pattern. The urinary excretion of 17-hydroxycorticosteroids and 17- ketosteroids showed low values. Studies with $I^{131}$ showed thyroidal uptake of $7.5 \%$ during 24 hours (normal, $10-35 \%$ ). Pulmonary function tests revealed significant reduction in the vital capacity and maximum breathing capacity. Chest roentgenogram revealed an antero-mediastinal mass with a left pleural effusion (figure). Follow-up films demonstrated gradual enlargement of the tumor. A left-sided thoracentesis yielded yellowish fluid having a specific gravity of 1.032 . Total protein of the fluid was $3.7 \mathrm{~g} / 100 \mathrm{ml}$ and cytologic findings were suggestive of malignancy. An electrocardiogram was normal. Electromyographic examination showed typical myotonic discharges. An edrophonium test was negative. 

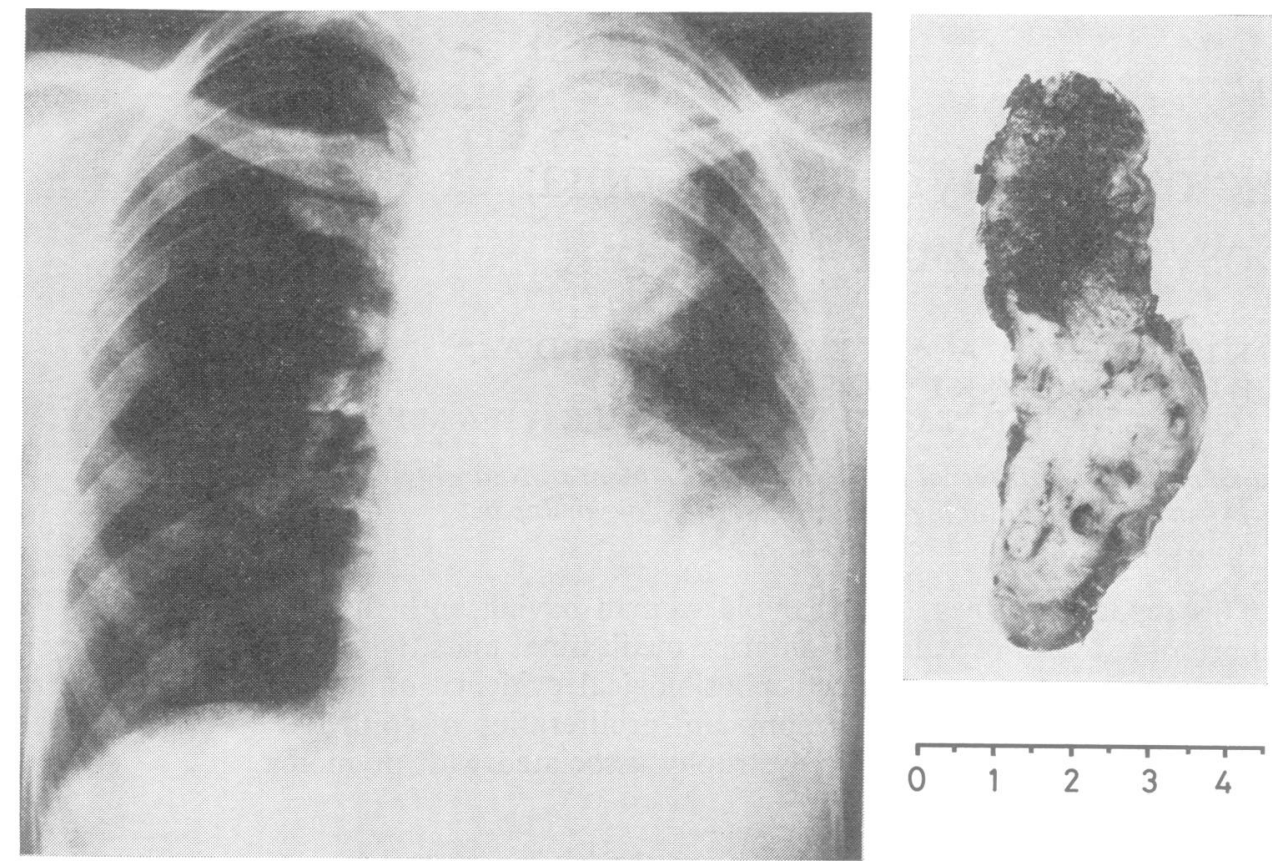

Figure On the left a chest roentgenogram showing a mediastinal tumour and a left pleural effusion. Macroscopic appearance of this tumour on postmortem examination is shown on the right.

In January of 1975 she had a sudden cardiac arrest and died. Postmortem examination disclosed remarkable atrophy of skeletal muscles which histologically showed lateral sarcoplasmic masses and central displacement of sarcolemmic nuclei. In the anterior mediastinum there was a firm and partly necrotic mass (figure). It was a relatively well-encapsulated tumor subdivided by fibrous trabeculae. Microscopically it was a thymoma of mixed type with predominant proliferation of epithelial cells, perivascular hyalinosis and metastasis to the regional lymphnodes. The spleen showed mild hyperaemia and lymphoid depletion. An adenoma of thyroid and a congenital hypoplasia of the left kidney also were noted.

\section{Discussion}

Myotonic dystrophy is a multisystemic disease inherited as an autosomal dominant trait. The clinical picture presented in this report was typical of this disease and our case shows a very rare combination of thymoma and myotonic dystrophy. A national survey of mediastinal neoplasms in Japan between 1970 and 1974 disclosed 417 cases of thymoma. ${ }^{2}$ The number of thymomas associated with myasthenia gravis was $95(22 \cdot 8 \%)$. However, the association of thymoma and myotonic dystrophy does not parallel that of thymoma and myasthenia gravis. Only one necropsy case of thymoma with myotonic dystrophy was encountered in our review of the literature. That patient was a 51 year-old Japanese man with a thymoma, myotonic dystrophy and a mixed tumour of the parotid gland. ${ }^{3}$ Warembourg ${ }^{4}$ reported a 66 year-old woman with an anterior mediastinal mass and "myotonic syndrome." However the histologic nature of this tumour was not investigated.

We recently described a high incidence of impaired reactivity to dinitrochlorobenzene in myotonic dystrophy. ${ }^{5}$ As a high incidence of anergy to dinitrochlorobenzene also has been found in malignancy, ${ }^{6}$ there are three possible explanations of anergy to dinitrochlorobenzene in our case; it could have been due to the myotonic dystrophy, to the thymoma or to both. The available data, however, do not provide a definite conclusion. Lymphocytopenia in our case was probably due to the thymoma. This case demonstrates a unique association of myotonic dystrophy and thymoma, although it is possible that this association may be coincidental.

\section{References}

1 Souadjian JV, Enriquez P, Silverstein MN, Pépin JM. The spectrum of diseases associated with 
thymoma. Coincidence or syndrome? Arch Int Med 1974; 134:374-9.

2 Teramatsu T, Yamamoto $H$, Matsutani $K$. National statistics on mediastinal neoplasms. 2. National statistics on the clinical characteristics of thymoma. J Japan Assoc Thoracic Surg 1976; 24:270-3.

3 Goto I, Ichimaru K, Maruyama T, Yamaguchi $T$. An autopsy case of myotonic dystrophy with familial diabetes mellitus, a mixed tumor of the parotid gland and a thymoma. Fukuoka Acta Med 1969; 60:126-133.

4 Warembourg $H$, Niquet $G$, Ducloux G, Lucaes
R, Spy E. Tumeur thymique et syndrome myotonique. A propos d'un cas. Lille Med 1964; 9: 35-8.

5 Kuroiwa Y, Sugita H, Toyokura Y, Mizoguchi $M$, Matsuo $\mathrm{H}$, Nonaka $\mathrm{Y}$. Immunologic derangement in myotonic dystrophy. Abnormal contact sensitization to dinitrochlorobenzene. $J$ Neurolog Sci 1980; 47:231-9.

6 Catalona WJ, Chretien PB. Abnormalities of quantitative dinitrochlorobenzene sensitization in cancer patients. Correlation with tumor stage and histology. Cancer 1973; 31:353-6. 